\title{
PREOPERATIVE PROTOCOL AND MORBIMORTALITY IN CERVICAL SURGERY WITH ANTERIOR APPROACH
}

\author{
PROTOCOLO PRÉ-OPERATÓRIO E MORBIMORTALIDADE EM CIRURGIA CERVICAL \\ COM ABORDAGEM ANTERIOR
}

\author{
PROTOCOLO PREOPERATORIO Y MORBIMORTALIDAD EN CIRUGÍA CERVICAL \\ CON ABORDAJE ANTERIOR
}

\author{
Luis Muñiz luna ${ }^{1}$ Edgar García Villarreal ${ }^{2}$, Fernando Guevara Villazón², Yadira Bahena Salgado², Mario Alonso Ciénega Valerio² \\ 1. "Hospital de Traumatología y Ortopedia Lomas Verdes", Edo. de México Poniente, Instituto Mexicano del Seguro Social, Mexico. \\ 2. UMAE HTOLV, IMSS, México.
}

\begin{abstract}
Objective: To determine the correlation between morbidity/mortality and the pre-surgical protocol in patients undergoing anterior cervical surgical approach. Methods: Retrospective, cross-sectional and descriptive study, in which 114 patients who underwent anterior cervical surgical approach were reviewed, divided into two groups: "Group A" Conventional Presurgical Protocol (CPP) and "Group B" Extended Presurgical Protocol (EPP). Statistical analysis used the IBM SPSS Statistics Base v.24 software. Results: We evaluated 114 patients, 35 from "Group A", 79 from "Group B", 83 (72.8\%) with cervical myelopathy, 30 (26.3\%) with cervicobrachialgia. "Group A" had 10 cases of respiratory failure, with 5 secondary to bronchial secretion, 2 secondary to cervical hematoma. "Group B" had 12 cases of respiratory failure, 3 secondary to bronchial secretion and 1 secondary to cervical hematoma. Conclusions: The extended presurgical protocol can be the answer to reduce complications by improving selection parameters of the candidate patient for a surgical procedure of the cervical spine. Level of Evidence III; Case-control study'.
\end{abstract}

Keywords: Spinal cord compression; Myelopathy; Spirometry; Respiratory insufficiency.

\section{RESUMO}

Objetivo: Determinar a correlação entre morbidade e mortalidade e o protocolo pré-cirúrgico, em pacientes submetidos à cirurgia de coluna cenvical anterior. Método: Estudo retrospectivo, transversal e descritivo, em 114 pacientes com cirurgia cenical anterior, dois grupos foram montados: "Grupo A" pré-cirúrgico convencional (PPP) e "grupo B" protocolo pré-cirúrgico estendido (PPE), a análise v.24 SPSS Statistics Base. Resultados: 114 casos de pacientes, 35 "Grupo A", 79 "grupo B", 83 (72,8\%) com a mielopatia cenvical, 30 (26,3\%) com cenicobraquialgia avaliada. No "Grupo A" forma relatados: 10 casos de insuficiência respiratória, 5 são secundárias a secreção brônquica, 2 são secundárias a hematoma cenvical. No "Grupo B" foram relatados: 12 casos de aflição respiratória, 3 são secreção brônquica secundária e um secundário ao hematoma cenvical. Conclusão: protocolo pré-cirúrgico estendido pode ser a resposta para reduzir as complicações, a partir do momento que se melhoram os parâmetros de seleção do paciente, que é candidato a um procedimento cirúrgico anterior da coluna cenvical. Nível de evidência III, Estudo de caso controleg.

Descritores: Compressão da medula espinal; Mielopatia; Espirometria; Insuficiência respiratória.

\section{RESUMEN}

Objetivo: Determinar la correlación entre la morbimortalidad y el protocolo prequirúrgico en pacientes sometidos a cirugía de la columna cervical por vía anterior. Métodos: Estudio retrospectivo, transversal y descriptivo, en el cual se revisaron 114 pacientes con cirugía cervical anterior, divididos en dos grupos: "Grupo A", Protocolo Prequirúrgico Convencional (PPC) y "Grupo B" Protocolo Prequirúrgico Extendido (PPE). El análisis estadístico se hizo con el software IBM SPSS Statistics Base v.24. Resultados: Se evaluaron 114 casos de pacientes, 35 del "Grupo A", 79 del "Grupo B", 83 (72,8\%) con mielopatía cervical, 30 (26,3\%) con cervicobraquialgia. El "Grupo A" tuvo 10 casos de insuficiencia respiratoria, con 5 secundarios a secreción bronquial, 2 secundarios a hematoma cenvical. El "Grupo B" tuvo 12 casos de insuficiencia respiratoria, 3 secundarios a secreción bronquial y 1 secundario a hematoma cervical. Conclusiones: El protocolo prequirúrgico extendido puede ser la respuesta para reducir las complicaciones mediante la mejoría de los parámetros de selección del paciente candidato a un procedimiento quirúrgico anterior de la columna cenical. Nivel de evidencia III; Estudio de caso control' ${ }^{\text {. }}$

Descriptores: Compresión de la médula espinal; Mielopatía; Espirometría; Insuficiencia respiratoria.

\section{INTRODUCTION}

Degenerative pathology of the cervical disc in its different phases can affect nerve structures, such as roots and the spinal cord, causing deficit and pain with serious impact to the quality of life. The anterior cervical surgical approach suggested by Leroy Abbot and described by Robinson \& Smith, in which they introduced the technique and the use of a bone graft to promote bone fusion of the anterior cervical segments, is frequently performed. ${ }^{1}$ The surgical treatment of cervical myelopathy is reserved for patients whose symptoms persist and who present progressive neurological 
dysfunction. The anterior approach has substantial advantages in the direct visualization of the affected sites and the minimal compromise to the muscular structures of the neck, however, disadvantages and complications have also been described, since there are vulnerable organs, such as the esophagus, the larynx, the trachea, and nerve and vascular structures that could be altered during surgical intervention. ${ }^{2}$ However, knowledge of the potential adverse events is critical to preventing or reducing their incidence and patients should be properly informed of the surgical risk. Therefore, the description and classification of adverse events can vary according to the surgeon, the patient, and the observer. Moreover, the adverse events vary according to their severity from mild to moderate or serious and permanent, and in some cases even to death. Acute serious complications are rare but, when they occur, they can be potentially mortal and present in during the time between the surgical event and the immediate postoperative period. These complications are all those that may restrict and compromise the airways, hindering breathing, such as edema of the glottis and larynx, paralysis of the glottis, lesion of the vertebral artery, spinal edema, neck hematoma, premature failure of the instrumentation and/or fixation system, as well as a delay in extubation, among others. Sugawara, mentions several risk factors, such as prolonged surgical time, revision surgery, and multilevel surgery. Obstruction of the airways following anterior cervical spine surgery caused by retropharyngeal hematoma or edema of the soft tissues has an incidence of from 1 to $6 \%$ globally. This can occur within minutes or up to 10 days following the surgery, but is more frequent within the first 24 to 48 hours after the surgical procedure. ${ }^{2}$

Daniels et al. also report that multilevel surgery ( $>2$ disc levels), bleeding more than $300 \mathrm{ml}$, and prolonged surgical time ( $>5$ hours) are risk factors for postoperative obstruction of the airways. Hematoma can occur due to venous bleeding or an unrecognized or insufficiently controlled arterial source. This adverse event can occur despite the postoperative placement of a drain and adequate hemostasis at the time the wound is closed due to an increase in arterial pressure, coughing, vomiting, coagulopathy, or from the use of anticoagulants. Specifically, an effort should be made to control the bleeding of the soft tissues and bone bleeding during the intervention. Postoperative measures can be used to protect the upper respiratory tract in the patients with a high risk of hemorrhage of the wound. ${ }^{2-4}$ The reported incidence of intraoperative tearing of the vertebral artery is quite low, in $0.3 \%$ of cases. The lesion mechanisms include excessively wide corpectomies, as well as the loss of the midline of the vertebral body or loss of orientation, which leads to an off-center or oblique corpectomy. Unrecognized tortuosity of the vertebral artery or the presence of infection in the vertebral body increases the risk of lesion. The spinal cord is at risk of lesion during all phases of anterior cervical surgery, with an incidence of spinal cord involvement of $0.2 \%$ to $0.9 \%$. Preventive strategies include the maintenance of systolic arterial pressure $<140 \mathrm{mmHg}$ and diastolic pressure $<80 \mathrm{mmHg}$ to prevent medullary ischemia. ${ }^{3}$

Some complications of anterior cervical surgery are caused by the trans-surgical retraction of the carotid artery, which is not well tolerated by some patients since it usually causes an increase in heart rate that leads to greater bleeding at the surgical site, as well as arterial hypotension and reduced cerebral reperfusion. The prolonged direct pressure applied to the esophagus and larynx by the automatic retraction system leads to edema, inflammation, and congestion, which can be a critical step in the development of respiratory difficulty. ${ }^{5}$

Patient characteristics that potentially influence the risk of respiratory problems include grade III obesity, obstructive sleep apnea, smoking, albumin $<3.5 \mathrm{~g} / \mathrm{dl}$, chronic obstructive pulmonary disease, cervical myelopathy, and previous surgery. Similarly, anesthetic factors that merit consideration include suboptimal visualization of the glottis according to the Mallampati classification or a problematic intubation process (multiple attempts). The variables that are statistically associated with compromise of the airways are exposure of more than three vertebral bodies, exposure of levels C2-C4, blood loss greater than $300 \mathrm{ml}$, and surgical time of more than 5 hours. ${ }^{6-9}$
For patients in the high-risk category for postoperative complications of the airways, a postoperative protocol that incorporates delayed extubation and monitoring in the intensive care unit (ICU) is indicated. There is controversy around the minimum elapsed time considered reasonable and safe prior to extubation. However, the average time reported for the development of airway complications following anterior cervical spine surgery ranges from 23 to 37 hours and maintaining intubation until the permeability of the airways has been confirmed and having clinical experience available in case of failed extubation are suggested. As such, the high-risk patient can be considered for extubation within the first 24 to 36 hours following surgery when they do not develop complications. Once extubated, they should be monitored in the ICU for a minimum of 4 to 6 hours before being transferred for hospitalization. ${ }^{6}$

The importance of the positioning of the patient to prevent complications and achieve successful results cannot be underestimated. Hyperextension of the neck in an attempt to increase exposure can result in the compression of the spinal cord and worsening of the myelopathy. ${ }^{7}$ Additionally, patients with spinal cord involvement are predisposed to deglutition with abnormalities. Obstruction of the upper airway in the anterior aspect of the cervical spine is a rare, but potentially lethal complication following surgery. Extensive dissections in the anterior cervical approach above $\mathrm{C} 4$ result in traumatized tissues and pharyngeal irritation. ${ }^{8}$

In general, the complications associated with anterior cervical fusion surgery are relatively rare, with reported rates ranging from $3.3 \%$ to $19.3 \%$. Dysphagia, pulmonary complications, and hematoma were the three most frequent adverse events. Advanced age and three or more comorbidities are among the factors associated with an increase in the complications rate. ${ }^{9}$

The concept of presurgical evaluation has been established for many years and has recently been incorporated into the process via surgery through the clinic. The final objective of presurgical evaluation is to facilitate a complete assessment of the risk each patient through targeted research that leads to appropriate decision making and the assignment of presurgical resources to benefit postsurgical recovery and the long-term outcome. The American College of Cardiology (ACC) together with the American Heart Association (AHA) define guidelines for the stratification of cardiac risk in non-cardiac surgery and identify three areas of evaluation:

1. Surgery-specific risk.

2. Patient-specific variables.

3. Exercise capacity.

Surgical risk increases with surgical complexity. Simple classification systems, such as the American Society of Anesthesiologists (ASA) classification, try to provide a general summary of the current state of the patient at the time of the evaluation. This scale is used worldwide and determines the clinical status of the patient, demonstrating prognostic relevance. ${ }^{10}$

Respiratory complications following surgery are frequent and include atelectasis, exacerbation of chronic disease, bronchospasm, and infection. The factors identified to assess the risk of pulmonary complications in non-cardiothoracic surgery include chronic obstructive pulmonary disease (COPD), 60 years old or older, ASA class 2 or higher, functional dependency, congestive heart failure, type of surgery, and low albumin $(<3.5 \mathrm{~g} / \mathrm{dl})$.

The National Institute of Health and Care Excellence (NICE) and its guidance on respiratory disease research accept that most tests are not prognostic and that routine chest radiographs (X-ray), arterial gas analysis, and pulmonary function tests (PFT) are of questionable value in many cases. ${ }^{10}$

\section{Functional research}

It is important to concentrate research resources whenever preoperative intervention and subsequent optimization guide and/or improve presurgical management and the postsurgical outcome. Any significant chronic disease can increase surgical risk and multiple investigations of a specific disease may be included in the preoperative assessment. More recently, evaluation of the preoperative functional 
state is gaining popularity. The objective of this approach is to focus the initial patient assessment on the "end result" of multiple comorbidities instead of investigating the specific entities of disease. In turn, this can eliminate the need for multiple investigations without guarantees in patients considered "fit for surgery" and focus more specialized research procedures on the high-risk group. This approach has been incorporated into the recent AHA/ACC guides, which have shown their importance in surgical prognosis and will probably improve preoperative risk stratification and perioperative intervention in the future. ${ }^{10}$

Patients with inadequate preoperative protocol who develop pulmonary complications may end up with serious problems, such as right-sided heart failure and mechanical ventilation support from inadequate ventilatory automatism at the time of extubation because of inspiratory muscle fatigue, prolonging the time in the hospital and in the intensive care unit with an increase in mortality. ${ }^{11}$

A double-blind prospective study conducted at the Mayo Clinic showed that stopping smoking for a period of 8 weeks was very effective in reducing the rate of postsurgical pulmonary complications (PPC). The people who quit smoking had a reduced PPC rate of only $12 \%$ as compared to those who continued to smoke with a PPC rate of $33 \%$. Even quitting smoking for the 12 to 24 hours before the operation can reduce the carboxyhemoglobin concentration to a normal level. It takes two months without smoking to improve the clearance of mucus by improving the activity of endobronchial ciliary function. The decrease in ciliary movement produces a significant reduction of sputum, which when present in the patients favors the appearance of atelectasis and silent aspiration leading to postsurgical pneumonic processes and important pulmonary involvement when associated with a ventilator. The presentation of sputum in the pre-surgical protocol requires a surgical deferral of approximately 10 days and prophylactic or directed antibiotic management. Nebulized bronchodilators should be used at least 24-48 hours before surgery to be effective. Some studies have indicated that bronchodilators are not very effective in patients with COPD. Although wheezing is reduced, forced expiratory volume for ne second (FEV1) is rarely improved by more than $10 \%$ of the pre-treatment values. ${ }^{11,12}$

\section{Preparation of the patient}

The preoperative environment provides a "teaching window" for the effective encouragement of physical training, quitting smoking and drinking, and instructions for physical respiratory therapy. For example, education in pulmonary expansion maneuvers reduce postsurgical pulmonary complications to a greater degrees when educational information is provided (Castillo and Haas, 1985). Muscle resistance training and a suitable diet can improve inspiratory muscle strength and facilitate weaning off the ventilator after major or prolonged surgeries. ${ }^{11,13}$

In the Spine Surgery Service of the High Specialty Medical Unit of the Hospital de Traumatología y Ortopedia Lomas Verdes of the IMSS, the number of patients treated for cervical spine pathology via the anterior cervical approach has increased over the past few years. There has also been an increase in perioperative complications, predominantly in the early postoperative period (the first 72 hours following surgery) and consequently, in the length of the hospital stay.

Serious and occasionally fatal complications during this period motivated a case review that showed an increase in the rate of patients with acute respiratory complications ranging from difficulty breathing from poor management of secretions, to edema of the glottis and larynx, to respiratory failure and sometimes respiratory arrest. In patients with ventilatory pulmonary insufficiency, critical lung function, prolonged and difficult mechanical ventilatory weaning increase nosocomial infections of the respiratory tract and an evident increase in hospital costs for the management of these comorbidities.

To address this scenario, we implemented a program to review the presurgical protocol of the patients who underwent anterior approach cervical spine surgery, determining that a high percentage of them were diagnosed with spondylotic cervical myelopathy, older than 60 years old, and with muscular limitations secondary to the myelopathy, and we detected patients with non-severe pulmonary restrictions not detectable by the conventional presurgical protocol. It was also evident that many of them had malnutrition disorders that put them at risk for lean mass loss in the early postoperative period with difficulty meeting the energy needs for premature weaning off of mechanical ventilation. The next step was to understand that the conventional presurgical assessment for an anterior cervical spine procedure usually focuses its research on parameters for predicting cardiovascular risk and the anesthetic risk of surgical intervention and rarely detects the minor aspects of the detriment to ventilatory capacity and pulmonary function that can overshadow the early prognosis of those treated by anterior cervical surgery. For this reason, we implemented a joint project with the intensive care unit and the internal medicine service for the presurgical detection of those subclinical aspects of the patient than can increase the risk of early and serious compromise of the airways and pulmonary ventilation.

It is called the Extended Presurgical Protocol for patients submitted to anterior cervical surgery and consists of the conventional preoperative evaluation plus the following study parameters: arterial gasometry, spirometry, serum proteins; and with the recommendation for additional measurements in the perioperative period such as an exercise program to improve lung capacity and function, both simple and against resistance, and simple micro-nebulizations prior to surgery and micro-nebulization with mucolytic agents after surgery, as well as surveillance in the intensive care unit (ICU) as a preventative measure to early extubation or as a measure to ensure the permeability of the airway in patients recommended for early extubation, all this with the intention of reducing early complications that compromise the airway and put the patient's life at risk. This protocol is designed specifically for patients submitted to anterior cervical surgery to evaluate respiratory and preoperative pulmonary function and nutritional state, to facilitate the management of lung secretions in the perioperative period, and to ensure that the patient has the muscular capacity for satisfactory ventilation and the physiological mechanisms to maintain timely circulatory homeostasis for postsurgical recovery when an anterior cervical approach is performed.

This assessment of the patient's respiratory function and nutritional state, using the spirometer to evaluate lung capacity, gasometry to evaluate blood oxygen capacity, and albumin and total proteins as nutritional state indicators, may be a way to select patients fit for surgery and have a beneficial impact on postoperative evolution. In addition, the presurgical use of nebulization could reduce the incidence of respiratory failures secondary to poor handling of bronchial secretions, despite some controversy in the literature over its use.

The objective of this study is to determine the correlation between morbidity/mortality and the presurgical protocol in patients submitted to anterior approach cervical spine surgery.

\section{METHODS}

This study was approved by the Institutional Review Board and registered as number R-2017-1501-30. It is a retrospective, cross-sectional, descriptive study that was conducted at the High Specialty Medical Unit of the Hospital de Traumatología y Ortopedia Lomas Verdes of the IMSS during a period of three years. The medical records of 114 patients who underwent anterior approach cervical surgery from 2005 to 2017 were reviewed and divided into two groups: Group A consisting of patients who followed the Conventional Presurgical Protocol (CPP) and Group B made up of patients with the Extended Presurgical Protocol (EPP). The data was collected in an Excel 2106 database for statistical analysis using IBM SPSS Statistics Base v. 24 software for the analysis and interpretation of the results using the descriptive statistics mean and standard deviation as frequencies for scalar variables and as percentages for nominal variables. The Pearson correlation was determined and a confidence level of $95 \%$ and statistically significant interval of $p<0.05$ were assumed. The study and their procedures are in accordance with the provisions of the Regulation of the General Health Law in the Health Research Matters, Title II, Chapter I, Article 17, Section I, risk-free research, which does not require informed consent, and with the 1975 Declaration of Helsinki, amended in 1989, current international codes and norms for good clinical research practices. 


\section{RESULTS}

Of the 114 cases of patients evaluated, 65 were men and 49 were women, with a mean age of 63 years ranging from $40-83$ years old. Thirty-five (30.7\%) of them belonged to Group A (CPP), with 26 men and 9 women, and the remaining 79 (69.2\%) belonged to Group B (EPP), with 39 men and 40 women.

Of the total sample, $83(72.8 \%)$ patients were diagnosed with cervical myelopathy, $30(26.3 \%)$ with cervicobrachialgia, and one $(0.8 \%)$ with structural deformity.

Among the patients in Group A ( $n=35), 10$ cases of respiratory failure were reported with a rate of $28.5 \%$ of the group and $8.7 \%$ of the total sample, five of which were secondary to bronchial secretion (14.2\%), two secondary to cervical hematoma (5.7\%), two to respiratory tract infection (5.7\%), and one with edema of the upper airways (2.8\%).

Among the patients in Group B ( $n=79), 12$ cases of respiratory failure were reported, with a rate of $15.1 \%$ of the group and $10.5 \%$ of the total sample, three of which were secondary to bronchial secretion (3.7\%), one secondary to cervical hematoma (1.2\%), five to respiratory tract infection (6.3\%), and three secondary to edema of the upper airways (3.7\%). (Table 1)

In Group A ( $\mathrm{n}=35)$, two cases of hypovolemic shock $(5.7 \%)$ and one case of dysphagia (2.8\%) were reported. In Group B ( $n=79)$, there were no cases of hypovolemic shock and 14 cases of dysphagia (17.7\%) reported.

As regards the number of days in the hospital, the patients in Group A spent an average of 3.9 days and three (8.5\%) patients were admitted to the ICU with an average of four days. In Group B, the average number of days in the hospital was 3.4 days and 10 patients were admitted to the ICU with an average of 4.2 days. This increase in the number of days in the ICU in Group B was because some patients entered the ICU as part of the postsurgical airway surveillance protocol. (Table 2)

In the statistical analysis, we looked for a correlation between the dependent and independent variables using the Pearson bivariate method. In the statistical analysis, we found a significant statistical relationship between the use of the EPP and the presence of bronchial secretions being lower in this group, with $p<0.044$. We did not observe any statistically significant correlation between the EPP and the complications of respiratory failure, hematoma, or edema of the upper airways, however, the overall percentage was lower in this group.

We found a statistically significant relationship between dysphagia and the EPP, with $p<0.03$. In addition, there was a statistically significant relationship, with $p<0.03$, between the CPP and the presence of hypovolemic shock.

In the patients in the EPP group who were in the ICU, a relationship to the presence of respiratory tract infection was observed, with $p<0.00$. We found a greater number of days in the hospital

Table 1. Causes of postoperative respiratory failure by patient group.

\begin{tabular}{c|c|c}
\hline Causes of Respiratory Failure* & $\begin{array}{c}\text { Group A (n= 10) } \\
\mathbf{2 8 . 5 \%}\end{array}$ & $\begin{array}{c}\text { Group B (n= 12) } \\
\mathbf{1 5 . 1} \%\end{array}$ \\
\hline Bronchial secretion & $5(14.2 \%)$ & $3(3.7 \%)$ \\
\hline Cervical hematoma & $2(5.7 \%)$ & $1(1.2 \%)$ \\
\hline Respiratory infection & $2(5.7 \%)$ & $5(6.3 \%)$ \\
\hline Edema of the upper airways & $1(2.8 \%)$ & $3(3.7 \%)$ \\
\hline
\end{tabular}

Table 2. Postoperative complications and hospital and ICU stays in patients who underwent anterior cervical surgery.

\begin{tabular}{c|c|c}
\hline Postoperative complications & $\begin{array}{c}\text { Group A } \\
\text { (n= 35) }\end{array}$ & $\begin{array}{c}\text { Group B } \\
\text { (n= 79) }\end{array}$ \\
\hline Respiratory failure $^{*}$ & $10(28.5 \%)$ & $12(15.1 \%)$ \\
\hline Hypovolemic shock & $2(5.7 \%)$ & $0(0 \%)$ \\
\hline Dysphagia & $1(2.8 \%)$ & $14(17.7 \%)$ \\
\hline Hospital stay (days) & 3.9 & 3.4 \\
\hline Stay in the Intensive Care Unit (days) & 4 & 4.2 \\
\hline
\end{tabular}

in patients with hypovolemic shock and respiratory failure due to secretions $(p<0.00$ and $p<0.001)$.

One patient was reported deceased from comorbidities associated with but not directly related to acute respiratory distress in the perioperative period. Only one patient was reported with transitory dysphonia in the extended protocol group and did not present any other complications.

\section{DISCUSSION}

The usefulness of an Extended Presurgical Protocol should be corroborated by clinical results. Other authors have initiated measures directed towards patients who underwent anterior approach cervical spine intervention with favorable results.

We must not fail to consider that using diagnostic and therapeutic strategies entails a cost for the institution. However, if the end result of these measures is reflected in a benefit to the patients such as a lower risk of the occurrence of complications, their use is justified.

Hamilton et al., in the chapter on postoperative management, report that pulmonary complications are more common than cardiac complications and they frequently cause prolonged hospital stays and higher morbidity and mortality. If the surgical procedures are extensive, if there has been a massive trauma, if the patient is elderly, or if the patient has a chronic preexisting disease or malnutrition, the ventilatory deterioration can be serious and may require assisted mechanical ventilation, which increases both hospitalization time and the complications derived from intubation, such as nosocomial pneumonia. Pneumonia rarely develops less than 4 or 5 days following the operation, unless an unusual event such as aspiration occurs. In our study, we found that the patients in Group B presented an increase in the occurrence of respiratory tract infection (6.3\%). Some of these patients were admitted to the intensive care unit as a protocol measure for postoperative surveillance of the airway after an anterior cervical approach, so this indication should only be considered in strictly necessary cases.

In relation to the number of days of the hospital stay, Hamilton et al. report that pulmonary complications cause prolonged hospitalizations. In our series, in Group A, in which spirometry tests were not performed, the patients with forced expiatory volume or forced vital capacity less than $70 \%$ were not identified, thus showing a higher risk of postsurgical pulmonary complications, presenting a higher average number of days in the hospital, and a discretely lower average number days in the ICU, only 0.2 days less than the Group B patients.

The incidence of obstruction of the airway following anterior cervical spine surgery caused by a retropharyngeal hematoma or edema of the soft tissues is reported as from 1-6\% in the global literature. In our study we observed an incidence of cervical hematoma of $5.7 \%$ in Group A and 1.2\% in Group B, being lower in the second group, and early detection and surgical drainage are indispensable for its control.

The rate of edema of the upper airways was 2.8\% in Group A and $3.7 \%$ in Group B, very similar to that reported by Sugawara in his studies, and we believe that this may be related to the placement of the automatic retractors or the prolonged surgical time, so early detection from signs such as dysphagia, hoarseness, difficulty swallowing, a drowning sensation, laryngeal wheezing, distress, and tracheal harshness are key to a favorable evolution.

In his study, Sugawara found an incidence of dysphagia of 2-6\% with risk factors that include being female, prolonged surgical time, and revision surgery. In our study we found a greater prevalence of dysphagia in Group B, which included a sample of 40 women with an incidence of $11.7 \%$, while in Group A the incidence was $2.8 \%$ with a greater sample of men. In both groups it was resolved transiently.

García Armengol et al. reported that the mortality rate was between $0 \%$ and $1.1 \%$ of cases and that most cases result from systemic complications. In our sample there was only one case $(0.8 \%)$ from a systemic cause, which proves that anterior cervical surgery is a safe procedure with low morbidity and mortality, but when they occur they can be disastrous and fatal. ${ }^{14,15}$ 
Spondylotic cervical myelopathy is the most frequent diagnosis for which anterior accesses of the neck to the cervical spine are performed, followed by cervicobrachialgia from the different phases of degenerative disc disease.

Respiratory failure is the most frequent cause of acute severe complications associated with the anterior approach to the cervical spine.

Poor management of bronchial secretions is the most frequent cause of early respiratory distress, followed by edema of the upper airways and hematoma of the neck in the retropharyngeal space.

Respiratory infections are the primary cause of late respiratory failure and are associated with an increase in the number of days in the hospital and of the days in the intensive care unit.

The Extended Presurgical Protocol showed a reduction of more than 13 percentage points in the prevalence of respiratory failure as compared to the Conventional Presurgical Protocol. The extended protocol also showed a decrease in the number of days in the hospital in comparison to the conventional protocol.

The extended protocol also showed statistical significance in the reduction of respiratory complications due to bronchial secretions.

Anterior approach cervical spine surgery is a simple technique and a surgically safe procedure with a low number of complications and a low mortality rate, but it is becoming more frequent and in recent years its indication has been expanded to a wide range of cervical spine pathologies with a growing patient rate. For this reason, it is advisable to prevent serious complications that compromise the airway, avoiding postoperative pulmonary complication and progressive deterioration, in addition to limiting the hospital medical care expenses. That is why the Extended Presurgical Protocol may be one of the many possible answers to reducing complications once that the selection parameters for a patient who is a candidate for an anterior cervical spine surgical procedure are improved and non-compliance with the parameter limits will delay the operative procedure until the patient is rehabilitated to improve their pulmonary capacity and function.

The stay in intensive care for surveillance of the airways in early extubation should be restricted to cases that, due to transoperative precedents and limitations, require it, since staying in the ICU is directly related to an increase in respiratory infections. This study has prognostic and design limitations, so multicenter cohort studies are recommended to be able to compare clinical and radiological results in the presence of these complications.

\section{ACKNOWLEDGEMENTS:}

To Dr. Rebeca Sarmina, medical chief of the Intensive Care Unit at the UMAE HTOLV for her valuable collaboration in the design of the extended presurgical protocol for patients undergoing anterior approach cervical spine surgery.

All authors declare no potential conflict of interest related to this article.

CONTRIBUTION OF THE AUTHORS: Each author made significant individual contributions to this manuscript. LM (0000-0003-2363-5589* ${ }^{\star}$ EG $(0000-$ 0003-3435-7414)*, and FG (0000-0001-8831-1767)* were the main contributors to the preparation of the manuscript. EG reviewed the clinical records of the patients and collected the data. YB (0000-0003-3777-4387)* and MA (0000-0001-7301-1681)* documented the cases in the clinical records. FG developed the statistical design. LM, EG, FG, and MA evaluated the statistical analysis data. EG and LM conducted the bibliographical research. LM, FG, and YB performed the final review of the manuscript and contributed to the intellectual concept of the study. ${ }^{*}$ ORCID (Open Researcher and Contributor ID).

\section{REFERENCES}

1. Garcia Armengol R, Colet Esquerre $\mathrm{S}$, Rodriguez PT, Abril MA, Cladellas- Ponsa JM, Panisello $\mathrm{CH}$, et al. Complicaciones del Abordaje Anterior en la patología de la columna cervical. Neurocirugia. 2007;18(3):209-20.

2. Sugawara T. Anterior Cervical Spine Surgery for Degenerative Disease: A Review. Neurol Med Chir (Tokyo). 2015;55(7):540-6.

3. Daniels AH, Riew KD, Yoo JU, Ching A, Birchard KR, Kranenburg AJ et al. Adverse Events Associated with Anterior Cervical Spine Surgery. J Am Acad Othop Surg. 2008;16(12):729-38.

4. Palumbo MA, Pelow Aiden JP, Daniels AH, Thakur NA, Caiati J. Airway Compromise Due to Wound Hematoma Following Anterior Cervical Spine Surgery. Open Orthopa J. 2012;6:108-13.

5. Zhang Y, Tian L, Zhao X, Wu Z, Wang L, Shi L, et al. Effect of Preoperative Tracheal Stretch Exercise on Anterior Cervical Spine Surgery: A retrospective study. J Spinal Disord Tech. 2015;28(10):E565-70.

6. Palumbo MA, Pelow Aiden J, Daniels AH, Bianco Aaron, Caiati JM. Airway compromise due to laryngopharyngeal edema after anterior cervical spine surgery. J Clin Anesth. 2013;25(1):66-72.

7. Tang S, Rao RD. Perioperative and Approach-Related Complications Associated with Anterior Cervical Surgery. Semin Spine Surg. 2009;21(3):148-55
8. Sagi HC, Beutler W, Carroll E, Connolly PJ. Airway Complications Associated with Surgery on the Anterior Cervical Spine. Spine (Phila Pa, 1976). 2002;27(9): 949-53.

9. Srinivasan D, La Marka F,Than KD, Patel RD, Park P. Perioperative characteristics and complications in obese patients undergoing anterior cervical fusion surgery. J Clin Neurosci. 2014;21(7):1159-62.

10. Burnside WS, Snowden C. Preoperative Assessment and Investigation. Surgery (Oxford). 2016; 35(2):63-8.

11. Azhar N. Pre-operative optimization of lung function. Indian J. Anaesth. 2015;59(9): 550-6.

12. Licker M, Scweizer A, Ellenberger C, Tschopp JM, Diaper J, Clergue F. Perioperative medical management of patiens with COPD. Int J Chron Obstruct Pulmon Dis. 2007:2(4) 493-515.

13. Li W, Zhao Y, Sun Z, Yang X, Lijuan Zhao, Shen J. Lung Protective effects of budesonide nebulization during perioperative period of thoracolumbar fusion. $J$ Thorac Dis. 2014,6(12):1800-7.

14. Zollinger $A$, Hofer CK, Pash T. Preoperative Pulmonary evaluation: facts and myths. Curr Opin Anaesthesiol. 2001,14(1):59-63.

15. Hamilton KM, Trost GR. Perioperative Management. Benzels Spine Surgery Techniques, Complication, Avoidance and Management. Fourth Edition. NewYork, Churcill Livingstone. 2017;(195): p. 1699-1710. 